\title{
High Prevalence of Hypertension and Other Cardiometabolic Risk Factors in US- and Caribbean-Born Blacks with Chest Pain Syndromes
}

\author{
Ayotunde Bamimore ${ }^{a, b}$ Oladipupo Olafiranye $e^{a, b} \quad$ Melaku Demede $^{a, b}$ \\ Ferdinand Zizi $^{\mathrm{a}}$ Ruth Browne ${ }^{\mathrm{a}}$ Cinton Brown ${ }^{\mathrm{a}}$ Samy I. McFarlane ${ }^{\mathrm{a}, \mathrm{c}}$ \\ Girardin Jean-Louis ${ }^{a}$ \\ ${ }^{a}$ Brooklyn Health Disparities Center, Department of Medicine, ${ }^{b}$ Division of Cardiovascular Medicine, and \\ 'Division of Endocrinology, Diabetes, and Hypertension, SUNY Downstate Medical Center, Brooklyn, N.Y., USA
}

\section{Key Words}

Cardiometabolic profile $\cdot$ Hypertension $\cdot$ Chest pain $\cdot$ Ethnicity

\begin{abstract}
Background: Caribbean-born blacks (CBB) have been reported to have lower coronary artery disease mortality rates than US-born blacks (UBB). We assessed whether CBB have a lower prevalence of cardiometabolic risk factors compared to UBB. Methods: Non-Hispanic blacks ( $\mathrm{n}=$ 275) hospitalized for chest pain who were prospectively enrolled in our Cardiovascular Outcomes Research Group (CORG) study provided clinical and demographic data. Results: The study cohort comprised $45 \%(n=125)$ UBB with a mean age of $61 \pm 16$ years and $55 \%(n=150)$ CBB with a mean age of $63 \pm 11$ years. Myocardial infarction was diagnosed in $33 \%$ of UBB and $36 \%$ of CBB. CBB had a lower rate of previous myocardial infarction (14 vs. $24 \% ; p=0.04$ ). They also smoked less ( 16 vs. $35 \% ; p=0.001$ ) and were less likely to have first-degree relatives with coronary artery disease ( $24 \mathrm{vs.} 41 \% ; p=0.018$ ). However, they had a similarly high prevalence of hypertension ( 99 vs. $98 \% ; p=0.99$ ), diabetes ( 58 vs. $48 \% ; p=0.11$ ), dyslipidemia ( 53 vs. $42 \% ; p=$ 0.08 ), and obesity (34 vs. $40 \% ; p=0.29$ ) as UBB. Conclusion: A very high prevalence of hypertension exists in non-Hispanic blacks hospitalized for chest pain. CBB and UBB have a similar prevalence of cardiometabolic profile in our study population. Besides smoking, other factors contributing to lower CHD mortality reported for CBB need to be further explored.
\end{abstract}




\section{CardioRenal Medicine}

\section{Background}

Coronary artery disease (CAD) continues to be the leading cause of death in all races and ethnic groups in the USA with the highest rates occurring in the black population [1]. The age-adjusted death rate for blacks as a result of CAD is 1.2 times greater than that of whites with a life expectancy that is 4.8 years lower [1]. Evidence suggests that blacks have a higher prevalence of risk factors that may contribute to the development of CAD, such as hypertension [2, 3], diabetes [4, 5], and physical inactivity [5], compared with their white counterparts. Research has shown a comparably high prevalence of smoking [6] and hypercholesterolemia [7] for both blacks and whites. Of note, black women have the highest obesity rates compared with women of other races in the USA [8]. Not only are these risk factors more common among blacks than among whites, there is also clustering of multiple risk factors in the black population [9].

Interestingly, as the literature on the disparities in the cardiovascular health of black and white populations continues to grow, it has become apparent from epidemiological studies that greater disparities exist within the black ethnic subgroups. A review of the 1990 US census data linked to New York City mortality data from 1988 to 1992 revealed that Caribbeanborn blacks $(\mathrm{CBB})$ of all ages have a $16 \%$ lower age-adjusted mortality rate from CAD compared with southern US-born blacks (UBB) [10]. However, little is known regarding differences in the prevalence of risk factors for CAD among black ethnic subgroups. Hence, in a prospective study, we tested the hypothesis that the prevalence of cardiometabolic risk factors is lower in $\mathrm{CBB}$ compared with UBB hospitalized for chest pain.

\section{Methods}

Data Source

In this study, we used the Cardiovascular Outcomes Research Group (CORG) registry of the State University of New York (SUNY) Downstate Medical Center and three affiliated hospitals which included Kings County Hospital, Brookdale University Hospital, and Staten Island University Hospital. The registry was designed to consecutively recruit patients (aged $>18$ years) admitted to any of the four hospitals for chest pain. The study protocol was approved by the Institutional Review Boards of SUNY Downstate Medical Center and the three affiliated hospitals.

\section{Participants}

Our study cohort included 275 self-identified non-Hispanic black patients who were prospectively enrolled into the CORG registry between April 2005 and January 2007. Information extracted from the registry for this cohort included demographic and anthropometric data, self-identified ethnic group, country of birth, presence or absence of hypertension, diabetes, dyslipidemia, current smoking, prior $\mathrm{CAD}$, renal failure, heart failure, peripheral vascular disease, history of CAD in first-degree relative, and body mass index (BMI). For study purposes, patients were categorized as UBB or CBB based on their place of birth.

\section{Statistical Analysis}

Group values were expressed as percentage and as mean \pm SD. Frequency and measures of central tendency were used to describe the sample. Continuous data were compared using the paired and unpaired Student's t tests, and the Fisher's exact test was used to compare the dichotomous variables. Differences in group proportions were assessed by a $\chi^{2}$ test with Yates' correction. All statistical analyses were performed using Statistical Package for Social Sciences 17.0 software (SPSS Inc., Chicago, Ill., USA). A p value of $<0.05$ was considered to be statistically significant. 


\section{CardioRenal Medicine}

Fig. 1. Comparison of prevalence of CAD risk factors in UBB and CBB.

Table 1. Comparison of sociodemographic and medical characteristics of $\mathrm{UBB}$ and $\mathrm{CBB}$

\begin{tabular}{l|l}
\hline Cardiorenal Med 2012;2:163-167 \\
\hline DOl: 10.1159/000337716 & $\begin{array}{l}\text { @ 2012 S. Karger AG, Basel } \\
\text { www.karger.com/crm }\end{array}$ \\
Published online: April 25, 2012 &
\end{tabular}

Bamimore et al.: Hypertension and Other Cardiometabolic Risk Factors in UBB and CBB

\begin{tabular}{lccc}
\hline Parameter & $\begin{array}{l}\text { UBB } \\
(\mathrm{n}=125)\end{array}$ & $\begin{array}{l}\text { CBB } \\
(\mathrm{n}=150)\end{array}$ & $\begin{array}{l}\mathrm{p} \\
\text { value }\end{array}$ \\
\hline Age, years & $61 \pm 16$ & $63 \pm 11$ & 0.18 \\
Male subjects & $49(39 \%)$ & $72(48 \%)$ & 0.18 \\
No high-school diploma & $39(31 \%)$ & $80(53 \%)$ & $<0.001$ \\
First-degree relative with CAD & $43(41 \%)$ & $29(24 \%)$ & 0.018 \\
Previous MI & $30(24 \%)$ & $20(14 \%)$ & 0.04 \\
PVD & $6(5 \%)$ & $9(6 \%)$ & 0.79 \\
Previous CVA & $6(5 \%)$ & $10(7 \%)$ & 0.45 \\
Heart failure & $14(11 \%)$ & $9(6 \%)$ & 0.19 \\
CKD & $14(11 \%)$ & $20(13 \%)$ & 0.48 \\
\hline \multicolumn{2}{c}{ MI = Myocardial infarction; PVD = peripheral vascular disease; } \\
CVA = cerebrovascular disease; CKD = chronic kidney disease. \\
\hline
\end{tabular}

\section{Results}

The study cohort comprised $45 \%(\mathrm{n}=125)$ UBB (mean age $61 \pm 16$ years, $39 \%$ male) and $55 \%(\mathrm{n}=150) \mathrm{CBB}$ (mean age $63 \pm 11$ years, $48 \%$ male). Myocardial infarction was diagnosed in $33 \%$ of UBB and $36 \%$ of CBB. Fewer UBB reported that they obtained a highschool diploma compared with CBB (53 vs. $31 \%$; $\mathrm{p}=<0.0001$ ). Other baseline characteristics are shown in table 1.

Although CBB smoked less (16 vs. $35 \%$; $\mathrm{p}=0.001$ ), had a lower frequency of previous history of myocardial infarction ( $14 \mathrm{vs.} 24 \%$; $\mathrm{p}=0.04$ ), and were less likely to have first-degree relatives with CAD ( 24 vs. $41 \%$; $\mathrm{p}=0.018$ ), they had a similarly high prevalence of hypertension ( 99 vs. $98 \%$; $\mathrm{p}=0.99$ ), diabetes ( 58 vs. $48 \%$; $\mathrm{p}=0.11$ ), dyslipidemia ( 53 vs. $42 \% ; \mathrm{p}=0.08$ ), and obesity (34 vs. $40 \%$; $\mathrm{p}=0.29$ ) as UBB (fig. 1).

\section{Discussion}

This study revealed a high prevalence of hypertension and other cardiometabolic risk factors in a population of non-Hispanic blacks hospitalized for chest pain. Surprisingly, both UBB and CBB had a similar prevalence of hypertension, diabetes, dyslipidemia, and obesity, 


\section{CardioRenal Medicine}

\begin{tabular}{l|l}
\hline \multicolumn{2}{l}{ Cardiorenal Med 2012;2:163-167 } \\
\hline DOI: 10.1159/000337716 & $\begin{array}{l}\text { @ 2012 S. Karger AG, Basel } \\
\text { www.karger.com/crm }\end{array}$ \\
\hline Published online: April 25, 2012
\end{tabular}

Bamimore et al.: Hypertension and Other Cardiometabolic Risk Factors in UBB and CBB

even though UBB had a relatively higher prevalence of smoking, previous myocardial infarction, and a greater likelihood of having a first-degree relative with CAD.

Research suggests that foreign-born blacks, particularly CBB, have lower CAD mortality rates $[10,11]$. Of note, life expectancy was found to be 9.4 years longer for CBB men and 7.8 years longer for CCB women compared with UBB [12]. Other studies also indicate that UBB have less healthy dietary habits, tend to be more obese, less active and have a higher 10 year risk of developing CAD compared with their foreign-born counterparts [13-15]. However, in the present study, we found a similar prevalence of hypertension, diabetes, dyslipidemia, and obesity in both $\mathrm{UBB}$ and $\mathrm{CBB}$. A possible explanation for this observation may be related to acculturation. It is well documented in the literature that the longer foreign-born blacks stay in the USA, the more likely they are to adopt a westernized lifestyle and the more their health status approximates that of their US-born counterparts. Kim et al. [16] reported that foreign-born New Yorkers generally reported better health outcomes compared with US-born individuals. In that study, increased duration of stay in the USA was associated with poor health of foreign-born individuals, even though their access to care and utilization of preventive services increased during this period. This decline in health was noticed after 4 years of residency in the USA [16].

Our finding of a higher prevalence of smoking in UBB compared with CBB is consistent with other studies $[13,14,17]$. Among 189 healthy individuals of African ancestry aged 18-40 years, smoking was more prevalent among US-born Afro-Caribbeans and African-Americans (blacks whose 2 parents were born in the USA) compared to foreign-born Afro-Caribbeans $[13,14]$. Similarly, in line with studies suggesting that CBB and other foreign-born blacks enjoy a health advantage compared with UBB $[16,18,19]$, we observed a higher prevalence of personal and family history of a previous myocardial infarction in UBB compared with CBB. Finally, we observed a staggering prevalence of hypertension in both UBB and $\mathrm{CBB}$ with almost the entire cohort being hypertensive. Community-based studies estimate the age-adjusted prevalence of hypertension among blacks older than 20 years of age at $41-$ $44 \%$ [20], increasing to $60 \%$ in blacks aged $45-84$ years [21]. The high prevalence of hypertension in our cohort may be related to a combination of their ethnicity, age, and the presence of multiple risk factors for CAD.

This study has several limitations. First, our study population was small in size and may not be generalizable to black individuals across their lifespan, as most individuals in the study were blacks who were older than 60 years of age. Second, we did not obtain information on dietary practices and length of stay in the USA. Other studies have shown the impact of acculturation on the prevalence of risk factors for CAD. Third, only black patients hospitalized for chest pain were included in our study. Most other studies enrolled young and healthy non-institutionalized patients or used data from surveys. We studied older patients (mean age 62 years) who were actually hospitalized for chest pain. It is, therefore, not surprising that we found a high prevalence of hypertension, diabetes, and dyslipidemia in the entire cohort. Future studies should assess variations in the prevalence of these risk factors among various black ethnic subgroups in community-based settings.

In conclusion, our study showed that a very high prevalence of hypertension exists in non-Hispanic blacks hospitalized for chest pain. CBB and UBB have a similar prevalence of cardiometabolic risk profile in our study population. Besides smoking, other factors contributing to lower CHD mortality reported for CBB need to be further explored.

\section{Acknowledgement}

This research was supported by funding from the NIH (R24 MD001090-01, R25HL105444, R01HL095799, and R01MD004113). 


\section{CardioRenal Medicine}

\begin{tabular}{l|l}
\hline \multicolumn{2}{l}{ Cardiorenal Med 2012;2:163-167 } \\
\hline DOI: 10.1159/000337716 & $\begin{array}{l}\text { @ 2012 S. Karger AG, Basel } \\
\text { www.karger.com/crm }\end{array}$ \\
Published online: April 25, 2012 &
\end{tabular}

\section{References}

1 Xu J, Kochanek KD, Murphy SL, Tejada-Vera B: Deaths: final data for 2007. Natl Vital Stat Rep 2010;58:1-135.

2 Rowland M, Roberts J: Blood pressure levels and hypertension in persons ages 6-74 years: United States, 1976-80. Adv Data 1982;84:1-12.

3 Keenan NL, Rosendorf KA; Centers for Disease Control and Prevention (CDC): Prevalence of hypertension and controlled hypertension - United States, 2005-2008. MMWR Surveill Summ 2011;60(suppl):94-97.

4 Beckles GL, Zhu J, Moonesinghe R; Centers for Disease Control and Prevention (CDC): Diabetes - United States, 2004 and 2008. MMWR Surveill Summ 2011;60(suppl):90-93.

5 Clark LT: Issues in minority health: atherosclerosis and coronary heart disease in African Americans. Med Clin North Am 2005;89:977-1001.

6 Garret BE, Dube SR, Trosclair A, Pechacek TF; Centers for Disease Control and Prevention (CDC): Cigarette smoking - United States, 1965-2008. MMWR Surveill Summ 2011;60(suppl):109-113.

$>7$ Third Report of the National Cholesterol Education Program (NCEP) Expert Panel on Detection, Evaluation and Treatment of High Blood Cholesterol in Adults (Adult Treatment Panel III) final report. Circulation 2002;106:31433421.

8 Freedman DS; Centers for Disease Control and Prevention (CDC): Obesity - United States, 1988-2008. MMWR Surveill Summ 2011;60(suppl):73-77.

-9 Ferdinand KC: Coronary artery disease in minority racial and ethnic groups in the United States. Am J Cardiol 2006; 97:12A-19A.

10 Fang J, Madhavan S, Alderman MH: The association between birthplace and mortality from cardiovascular causes among black and white residents of New York City. N Engl J Med 1996;335:1545-1551.

- 11 Singh GK, Siahpush M: Ethnic-immigrant differentials in health behaviors, morbidity, and cause-specific mortality in the United States: an analysis of two national data bases. Hum Biol 2002;74:83-109.

12 Singh GK, Miller BA: Health, life expectancy, and mortality patterns among immigrant populations in the United States. Can J Public Health 2004;95:I14-I21.

13 Davis EE, Huffman FG: Behavioral risk profiles for coronary heart disease among apparently healthy individuals of African ancestry. Ethn Dis 2006;16:114-119.

14 Davis EE, Huffman FG: Differences in coronary heart disease risk markers among apparently healthy individuals of African ancestry. J Natl Med Assoc 2007;99:658-664.

15 Lancaster KJ, Watts SO, Dixon LB: Dietary intake and risk of coronary heart disease differ among ethnic subgroups of Black Americans. J Nutr 2006;136:446-451.

16 Kim M, Van WG, Kerker B, Thorpe L, Frieden TR: The Health of Immigrants in New York City. New York City Department of Health and Mental Hygiene publication, 2006, pp 1-27.

-17 Bennett GG, Wolin KY, Okechukwu CA, Arthur CM, Askew S, Sorenson G, Emmons KM: Nativity and cigarette smoking among lower income blacks: results from the Healthy Directions Study. J Immigr Minor Health 2008;10: 305-311.

18 Hamilton TG, Hummer RA: Immigration and the health of US black adults: does country of origin matter? Soc Sci Med 2011;73:1551-1560.

19 Stephen EH, Foote K, Hendershot GE, Schoenborn CA: Health of the foreign-born population: United States, 1989-90. Adv Data 1994;14:1-12.

20 National Center for Health Statistics: Health, United States, 2010: With Special Feature on Death and Dying. A US Department of Health and Human Services publication, 2011, pp 1-563.

-21 Kramer H, Han C, Post W, Goff D, Diez-Roux A, Cooper R, Jinagouda S, Shea S: Racial/ethnic differences in hypertension and hypertension treatment and control in the multi-ethnic study of atherosclerosis (MESA). Am J Hypertens 2004;17:963-970. 